\title{
ANÁLISE DA CICATRIZAÇÃO NA LINHAALBA COM USO DE EXTRATO AQUOSO DE Orbignya phalerata (BABAÇU). ESTUDO CONTROLADO EM RATOS ${ }^{1}$
}

\author{
Analysis of healing in the Alba Linea with the use of Orbignya phalerata (babassu) water \\ extract. Controlled study in rats
}

\begin{abstract}
Sebastião Barreto de Brito Filho ${ }^{3}$, Jorge Eduardo F. Matias ${ }^{4}$, Henrique Jorge Stahlke Júnior ${ }^{4}$, Orlando Jorge Martins Torres ${ }^{2}$, Jorge Rufino Ribas Timi ${ }^{4}$, Sérgio Bernardo Tenório ${ }^{4}$, Elizabeth Milla Tâmbara ${ }^{4}$, Ângelo G. Carstens ${ }^{5}$, Richard Vieira Campos 5 , Márcio Myamoto ${ }^{5}$
\end{abstract}



\section{RESUMO}

Introdução: O mesocarpo do babaçu (Orbignya phalerata) tem sido utilizado em estudos experimentais para verificar a sua ação antiinflamatória. No Maranhão, é muito utilizado como alimento e como remédio popular para cicatrização de ferimentos. Objetivo - Avaliar macroscópica, histológica e tensiometricamente, a ação do extrato de Orbygnia phalerata no processo de cicatrização de laparotomias medianas em ratos. Métodos: Quarenta ratos da linhagem Wistar, adultos, machos, foram utilizados em procedimento experimental que consistiu em uma incisão na linha alba e síntese em plano único com pontos separados de fio de polipropileno 5-0. Após esse procedimento comum, os animais foram distribuídos em dois grupos de 20. Ao grupo chamado controle, foi utilizado injeção intraperitoneal, em dose única de $1 \mathrm{~mL}$ de soro fisiológico para cada quilo de peso. Ao grupo experimento, utilizou-se solução aquosa de babaçu na dose de $50 \mathrm{mg}$ por quilo de peso. Os animais foram acompanhados e mortos após três e sete dias, procedendo-se, a seguir, à análise tensiométrica e histológica. Resultados: O exame macroscópico não mostrou presença de aderências importantes entre a linha alba e os órgãos intra-abdominais nos grupos de estudo. A avaliação histológica mostrou efeito marginalmente significativo $(\mathrm{p}=0,086)$ para inflamação aguda nos grupos controle e experimento de três dias e efeito significativo $(\mathrm{p}=0,003)$ para a reação gigantocelular $(\mathrm{p}=0,003)$. Diferença significativa $(\mathrm{p}-=0,023)$ foi observada para inflamação aguda no grupos controle experimento de sete dias. $\mathrm{Na}$ análise intra-grupo (controle três e sete), foi observado efeito marginalmente significativo $(\mathrm{p}=0,094 \mathrm{e} p=0,05)$ respectivamente para as variáveis inflamação aguda e crônica. Na análise somente entre os grupos experimentos, as variáveis reação gigantocelular $(0,002)$ e colagenização $(0,016)$ apresentaram resultado significativo. A avaliação tensiométrica mostrou diferença significativa em relação ao grupo experimento de sete dias, que ofereceu melhor resistência do que os outros grupos. Conclusão: As avaliações histológica e macroscópica não mostraram diferenças significativas entre o extrato e a solução salina; quanto à tensiométrica, o grupo experimento de sete dias apresentou diferença significativa em relação ao grupo controle de mesmo período de pós-operatório, sugerindo indícios de que o uso do extrato administrado intraperitonealmente favorece o processo de cicatrização.

Descritores: Orbignya phalerata. Óleos Vegetais.Linea Alba. Cicatrização de Feridas. Ratos.

\begin{abstract}
Introduction: The babassu mesocarp (Orbignya phalerata) has been used in experimental research studies focused on its antiinflammatory action. In state of Maranhão - Brazil it is widely used not only as food, but also as popular medicine in wound healing process. Purpose: To evaluate the action of Orbignya phalerata extract in macroscopic, histologicic and tensiometric aspects in the healing process of median laparotomy in rats. Methods: Forty male adult Wistar rats were submitted to an incision in the alba linea, sutured back in one plan with separated stitches of polypropilene 5-0. After regular procedure, the animals were divided into two groups of 20 rats each. To the group named control an intraperitoneal, dose of $1,0 \mathrm{ml}$ of saline solution per kilogram of body weight was done. To the experimental group, the same thing was also done, but instead of saline solution it was injected water solution of babassu, in a dose of $50 \mathrm{mg} / \mathrm{kg}$. The animals were observed in the following days. All of them were killed within a three and seven day post-operative period schedule, and then a histological and tensiometric analysis was carried out. Results: On macroscopic examination no relevant adherence, between the alba linea and the abdominal organs in the study groups, was found. Histological evaluation presented marginal significant effects $(p=0,86)$ to acute inflammation and significant effects $(p=0,003)$ to giant cell reaction in both
\end{abstract}


control and experimental three days groups. Significant difference was observed to acute inflammation in both seven days control and experimental groups. In the intragroup analysis (control three and seven) some marginal significant effect was in relationship to acute and chronic inflammation. In the interexperimental groups analysis, only the giant cell reactions $(0,002)$ and colagenization had significant results. The tensiometric evaluation showed in the seven day experimental group more resistence then others. Conclusion: The macroscopic and histological evaluation didn't show any significant difference between the experimental and control groups, but the tensiometric evaluation at the 7th day experimental group had significant difference compared to the control group, signalizing that the use of the extract of babassu intraperitoneally injected can improve the healing process.

Key Words: Orbignya phalerata. Plant Oils. Alba Linea. Wound Healing. Rats.

\section{Introdução}

O despertar para a cicatrização dos ferimentos é remoto, pois desde os primórdios da ciência, a ferida parece ter sido a primeira interferência clínico-cirúrgica reconhecida pelo homem. É natural que, com a evolução proporcionada pelo amadurecimento e novos conhecimentos da humanidade, a procura por novas técnicas e drogas que pudessem melhorar a cicatrização dos tecidos se tornasse rotineira nas pesquisas científicas.

A cicatrização das feridas é processo complexo, envolvendo vários fatores, tais como: inflamação, quimiotaxia, proliferação celular, diferenciação e remodelação, que são agrupados em três fases: a inflamatória, a de fibroplasia ou proliferativa e, por último, a de maturação ou remodelação ${ }^{1}$.

Na primeira fase, com duração de três a quatro dias, destaca-se o aumento da permeabilidade vascular permitindo o aporte prevalente de mononuclerares, principalmente os macrófagos, que promovem a digestão do tecido morto.

A fase seguinte, durando de três a quatro semanas, caracteriza-se pelo aparecimento de fibroblastos, cuja principal fonte são as células mesenquimais locais e aquelas da adventícia dos vasos. A participação dos fibroblastos é importante pela sua intensa capacidade de síntese protéica e multiplicação celular, produzindo substância fundamental e colágeno.

Finalmente, na fase de maturação ou remodelação, permanecem a proliferação de fibroblastos e deposição de colágeno, o qual comprime os capilares neoformados, diminuindo a vascularização e provocando a queda da produção de substância fundamental.

A atividade metabólica dos fibroblastos que invadem a região sob reação inflamatória irá contribuir para a formação do chamado tecido de granulação, importante para o processo de epitelização final, tal como o são os monócitos e neutrófilos.

Elementos positivos e negativos podem interferir no processo e determinar alterações morfológicas e químicas nas três fases acima descritas.

A ferida operatória torna-se, muitas vezes, de difícil cicatrização quando fatores externos, alheios à vontade do cirurgião, como edema, infecção e desnutrição sobrepõemse, e muitos esforços têm sido feitos para diminuir estas circunstâncias indesejáveis.

O processo de cicatrização tem sido amplamente estudado e abordado em diferentes linhas de pesquisa com o objetivo de otimizá-lo, abrangendo aspectos diversos como, por exemplo, fisiopatologia, fatores de risco, drogas antiinflamatórias e substâncias químicas que possam interagir com a cicatrização.

A procura de novos procedimentos cirúrgicos e/ou novas drogas que possam interferir nesse processo tornou-se quase uma obsessão nos dias atuais. Tognini et al. (1998) ${ }^{2}$ comprovaram em animais que o uso de diclofenaco de sódio produz menor quantidade de fibras colágenas no $7^{\circ}$ e no $14^{\circ}$ dia de pós-operatório, sugerindo que esse medicamento causaria retardo nos processos de reparação tecidual na parede abdominal.

Outros autores como Ehrlich e Hunt(1968), citados por Tognini et al. $(1998)^{2}$, cogitaram que o uso de antiinflamatórios determina atraso no aparecimento de fibroblastos, da neo-formação vascular e da reepitelização da ferida, demonstrando que seu uso inibe maior aporte de fibras colágenas, sugerindo ser de uso prejudicial no processo da cicatrização.

$\mathrm{Na}$ fase final da cicatrização, as feridas podem apresentar colagenases que atuariam na posterior absorção de parte do colágeno ${ }^{3}$. A colagenase age especificamente quando ainda há inflamação aguda, realizando a degradação do colágeno instável com maior eficácia, contribuindo para a transformação de tecido inflamatório para tecido conjuntivo jovem.

O uso de plantas com fins terapêuticos nas mais variadas enfermidades é milenar. No Estado do Maranhão - Brasil, a abundância da palmeira de babaçu propicia ampla oportunidade de sua utilização para diversos fins, inclusive, científicos. A Orbignya phalerata tem sido motivo de investigações envolvendo possíveis ações terapêuticas.

Estudos existem ${ }^{4}$ que não mostraram atividade analgésica ou antiinflamatória ao babaçu, mas ele tem sido investigado ainda que de forma inicial e incipiente, como cicatrizante em geral. Se ele efetivamente exerce este efeito e como ele o faz, é desconhecido.

Estudo recente da Orbignya phalerata mostra efeito antiinflamatório e imunomodelador e conclui que o seu uso com fins terapêuticos deve fazer parte da tradicional medicina popular brasileira ${ }^{5}$.

De maneira geral, no uso popular, a farinha de babaçu é utilizada como antiinflamatório na cura de feridas crônicas, dentre outras aplicações ${ }^{6}$.

Não se entende, ainda, o mecanismo favorecedor de todos os fenômenos relacionados ao babaçu e pouco tem sido publicado a respeito. Portanto, estudos com metodologia científica adequada para provar o que o dito popular tem de verdadeiro, devem ser incentivados.

Assim, este trabalho tem por objetivo analisar com- 
parativamente as alterações macroscópicas, histológicas e tensiométricas proporcionadas pelo uso do extrato aquoso do babaçu na cicatrização da linha alba em ratos.

\section{Material e Método}

Este estudo foi efetuado no Laboratório de Pesquisa do Departamento de Fisiologia e Farmacologia do Centro de Ciências Biológicas e da Saúde da Universidade Federal do Maranhão (UFMA), obedecendo as normas do Colégio Brasileiro de Experimentação Animal (COBEA) e foi aprovado pelo Comitê de Ética em Pesquisa da UFMA.

Quarenta ratos da espécie Rattus Novergiicus Albinus, machos adultos da linhagem Wistar, de peso variando entre 90 a 110 gramas, foram aleatoriamente distribuídos em dois grupos de 20 (grupos controle e experimento), disponibilizados em gaiolas. Cada um desses grupos foi subdividido em subgrupos de 10, de acordo com o dia de sua morte: grupo experimento três dias (GE3D); grupo experimento sete dias (GE7D); grupo controle três dias (GC3D) e grupo controle sete dias (GC7D).

\section{Preparo do extrato da Orbignya phalerata}

A planta, catalogada sob o n ${ }^{\circ} 1136$ no Herbário Ático Seabra na UFMA, foi coletada e o seu mesocarpo identificado e isolado a partir do coco (Figura 1).



FIGURA 1 - Coco do babaçu. Legenda: A) Epicarpo; B) Mesocarpo; C) Endocarpo.; D) Amêndoa

Com o auxílio de uma espátula, separou-se o mesocarpo que ficou exposto sobre bancada durante três dias para secar. Depois de seco, ele foi colocado em estufa a temperatura de 450C durante 24 horas para retirada final da umidade. O pó, em forma de farinha, foi obtido após moagem em moinho elétrico no Laboratório do Pavilhão Tecnológico da UFMA. O extrato aquoso foi feito após pesagem do pó do mesocarpo que foi diluído em solução salina para con- centração de $25 \mathrm{mg} / \mathrm{ml}$.

\section{Etapas experimentais}

Os ratos foram alojados em gaiolas com cinco animais em cada, identificados e pesados. O ciclo dia e noite, iluminação, aeração, temperatura e umidade foram ambientais. Alimentação com ração padrão para ratos e água ad libitum foram proporcionados durante sete dias de pré-operatório para adaptação. Realizou-se jejum de seis horas no pré-operatório e ficha protocolo foi estabelecida para cada animal. Foram feitas cinco marcas para identificação diferentes nas amostras de cada gaiola: cabeça, cauda, lateral direito, lateral esquerdo e sem marca.

O procedimento anestésico consistiu em indução com éter sulfúrico por inalação em campânula de plástico fechada, contendo algodão umedecido com éter até atingir o nível de anestesia referido pelo desaparecimento dos reflexos palpebrais. A manutenção do plano anestésico se deu por sistema semi-aberto sob máscara artesanal.

Os animais, após pesados e identificados com ácido pícrico, foram imobilizados em decúbito dorsal horizontal, por meio de fita adesiva presas aos quatro membros nas extremidades da prancha. O procedimento operatório seguiu padronização para os animais de ambos os grupos.

Após epilação na região anterior do abdômen com antisepsia da região com polivinilpirrolidona-iodo, realizou-se incisão longitudinal mediana de $3 \mathrm{~cm}$ a partir do processo xifóide, comprometendo pele e plano músculo-aponeurótico, seguido de abertura da cavidade peritoneal. A seguir, administrou-se na cavidade extrato aquoso de babaçu na dose única de $50 \mathrm{mg} / \mathrm{kg}$ ou solução salina de acordo com o grupo (experimento ou controle). A síntese foi feita com seis pontos simples e separados a $0,5 \mathrm{~cm}$ das bordas da ferida e com espaçamento de $0,5 \mathrm{~cm}$ entre um ponto e outro interesando os planos peritoneal e músculo-aponeurótico com fio de polipropileno monofilamentado 5-0. A pele foi suturada com o mesmo fio em sutura contínua, seguindo-se de anti-sepsia final no ferimento cirúrgico com polivinilpirrolidona-iodo.

Ao final do ato operatório, os animais foram reconduzidos às suas respectivas gaiolas em condições iguais as do período pré-operatório mostrando o dia da operação e o tipo do grupo (controle ou experimento). Na avaliação diária, foram observadas e registradas as condições da ferida e intercorrências.

Para morte, os animais foram colocados sob inalação contínua de éter sulfúrico em recipiente fechado até que ocorresse o óbito sendo então pesados e fixados à prancha cirúrgica do mesmo modo que no ato operatório. A seguir, procedia-se a excisão de segmento retangular com dimensões de 4,5 cm crânio-caudal e 3,5 cm látero-lateral, abrangendo a incisão operatória, tecidos circunjacentes e toda a espessura da parede abdominal (Figura 2).

$\mathrm{O}$ inventário da cavidade foi efetuado com o intuito de verificar a existência de abscessos e/ou deiscências de sutura e aderências. Utilizou-se o escore de adesão de $\mathrm{Nair}^{7}$ para a quantificação macroscópica das aderências (Quadro1). 


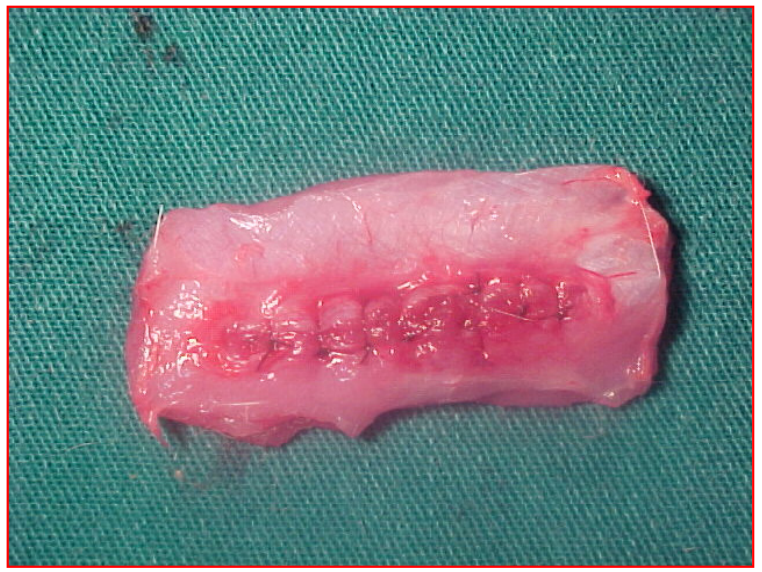

FIGURA 2 - Peça cirúrgica excisada em todo a espessura da parede abdominal

QUADRO 1- Escore de adesão de Nair ${ }^{7}$

\begin{tabular}{|c|l|}
\hline Grau & \multicolumn{1}{|c|}{ Achado } \\
\hline 0 & Sem adesão \\
\hline I & $\begin{array}{l}\text { Adesão única entre dois órgãos ou entre um órgão } \\
\text { e a parede abdominal }\end{array}$ \\
\hline II & $\begin{array}{l}\text { Duas adesões entre órgãos ou um órgão e a parede } \\
\text { abdominal }\end{array}$ \\
\hline III & $\begin{array}{l}\text { Mais de duas adesões entre órgãos ou uma massa } \\
\text { de adesão generalizada do intestino sem aderir à } \\
\text { parede abdominal }\end{array}$ \\
\hline IV & $\begin{array}{l}\text { Aderência generalizada entre órgãos e a parede ou } \\
\text { aderência maciça entre todos os órgãos }\end{array}$ \\
\hline
\end{tabular}

Da peça cirúrgica foi retirada uma faixa horizontal de $1 \mathrm{~cm}$ para exame histopatológico e colocada em formol a $10 \%$. O restante da peça foi colocado em outro frasco com solução salina a $0,9 \%$ para estudo tensiométrico. Cada frasco recebeu identificação com o nome do grupo, subgrupo e identificação do animal.

O estudo tensiométrico foi realizado logo após a morte dos animais no Laboratório de Física do Centro Federal Tecnológico do Maranhão (CEFET/MA), com equipamento computadorizado (Figura 3) e avaliação final por gráficos. A máquina utilizada foi a universal de ensaio (modelo TT 2420, TIRA Maschinenbau Gmbh) equipada com uma célula de carga com capacidade máxima de 20 quilonewton e precisão de $0,5 \%$. As deformações foram medidas através do deslocamento do carro superior do equipamento com precisão pois não há praticamente escorregamento da amostra dentro das garras de fixação.

O estudo tensiométrico foi efetuado na totalidade das peças cirúrgicas retiradas, obedecendo a protocolo padrão de avaliação.

Inicialmente após ser fixado na máquina, o comprimento da peça cirúrgica foi medido com um paquímetro de precisão, com prévia pré-carga de 2 newtons(N), e tempo de acomodação de 60 segundos. A velocidade estabelecida para todos os ensaios foi de $5 \mathrm{~mm} /$ minuto e as medidas foram realizadas a cada $0,5 \mathrm{~mm}$.
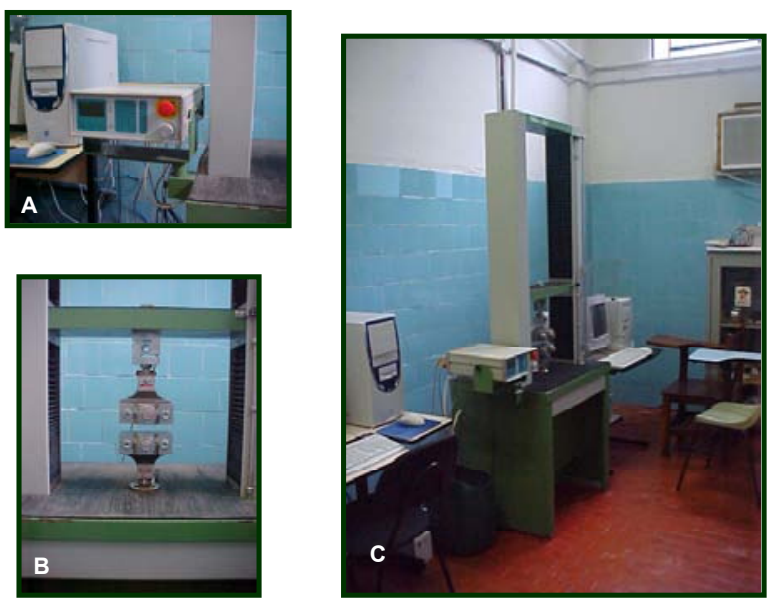

FIGURA 3 - Máquina universal de ensaios. LEGENDA: A) Controle digital; B) Garras para tração; C) Sala de avaliação tensiométrica

As peças estudadas foram pesadas antes do ensaio, em balança digital com precisão de 0,01 grama.

Após a fixação das amostras nos acessórios da máquina universal de ensaios, elas foram submetidas à tração axial, até ser atingido decréscimo de $50 \%$ do valor da carga máxima. Ultrapassando esse limite máximo, registraram-se as cargas correspondentes a cada deformação medida. Após a realização de cada ensaio, foi realizada inspeção do local de ruptura da peça.

Com os gráficos de carga versus deformação, obtidos de cada ensaio, foram calculadas as propriedades mecânicas limite máximo. A Figura 4 ilustra como foi determinada essa propriedade, sendo que LM representa o limite máximo, Cmáx a carga máxima e Dmáx a deformação na carga máxima sofrida pela amostra.

O limite máximo (LM) é o maior valor da carga e da deformação observada em cada ensaio, até o rompimento da seção da amostra.

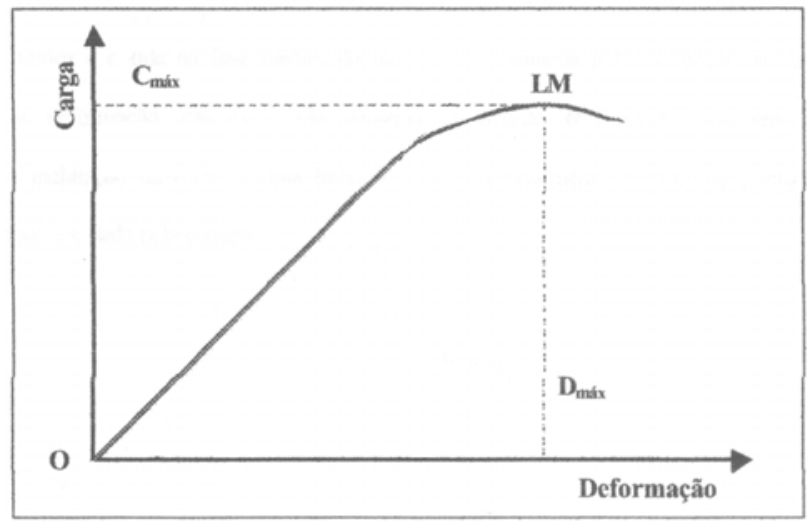

FIGURA 4 - Carga versus deformação, a partir do qual são obtidas as propriedades mecânicas. LEGENDA: Cmax - carga máxima, Dmax - deformação máxima e LM - limite máximo 
As peças fixadas em formol a $10 \%$ foram encaminhadas para o Laboratório de Histologia da UFMA e os processos de rotina foram realizados para a coloração pela Hematoxilina-Eosina (HE). O estudo microscópico em oito campos por lâmina analisou o processo de reparação tecidual (processo inflamatório quanto à presença de infiltrado inflamatório em sua intensidade, distribuição no tecido de sustentação e tipo de células presentes ) e a morfometria de colágeno presente na linha de sutura, sendo os dados assinalados em protocolo de avaliação histológica.

Os dados foram analisados estatisticamente utilizandose o programa Statistica for Windows 5.1. As variáveis tensiométricas, ou seja, a carga máxima (CMAX) e a deformação máxima (DMAX), bem como, o peso inicial e peso final foram analisados pelo teste $t$ de Student. Para se avaliar conjuntamente os efeitos dos grupos controle e experimento e a interação entre eles fez-se análise de variância (ANOVA) com dois fatores. As variáveis da avaliação histológica foram analisadas pelo teste não-paramétrico de Mann-Whitney. Em todos os testes foram feitas análises intergrupo (controle e experimento) e intragrupo (controle 3D - controle 7D; experimento 3D - experimento 7D). O nível de significância (a) utilizado para se rejeitar a hipótese da nulidade foi de 0,05 .

\section{Resultados}

Os animais apresentaram pós-operatório sem complicações, permanecendo vivos até o final do experimento.

\section{Avaliação macroscópica}

\section{Variáveis quantitativas}

As variáveis Cmax e Dmax não apresentaram resultado significativo ao nível de 5\% tanto para grupo de três e sete dias; contudo Dmax para o grupo de sete dias apresentou resultado marginalmente significativo $(\mathrm{p}=0,085)$.(Figuras 5 e 6$)$

A análise de variância para os grupos controle e experimento, demonstrou que o grupo experimento de sete dias apresentou maior resistência em relação à carga máxima, com $\mathrm{p}<0,7082$.(Figura 7).

A análise de variância para o grupos controle e experimento (intergrupo) mostrou maior Dmax no grupo experimento de sete dias, evidenciando dessa forma maior resistência à tração $(\mathrm{p}<0,0732)($ Figura 8$)$.

\section{Avaliação microscópica}

Os resultados demonstraram que os ratos mortos no $3^{\circ}$ dia de pós-operatório, tanto no grupo controle quanto no experimento, tiveram predomínio de processo inflamatório crônico granulomatoso, com exceção de um animal onde predominou processo inflamatório crônico inespecífico (Figuras 9 e 10).

\section{Avaliação macroscópica}

A totalidade dos ratos evoluiu sem complicações (fístulas, deiscências ou abscessos) da ferida operatória na parede



FIGURA 5 - Variável Cmax com média e desvio padrão dos grupos controle e experimento. Legenda: C3 = GC3D, E3 = GE3D, C7 $=\mathrm{GC} 7 \mathrm{D}, \mathrm{E} 7=\mathrm{GE} 7 \mathrm{D}$ 


\section{0}

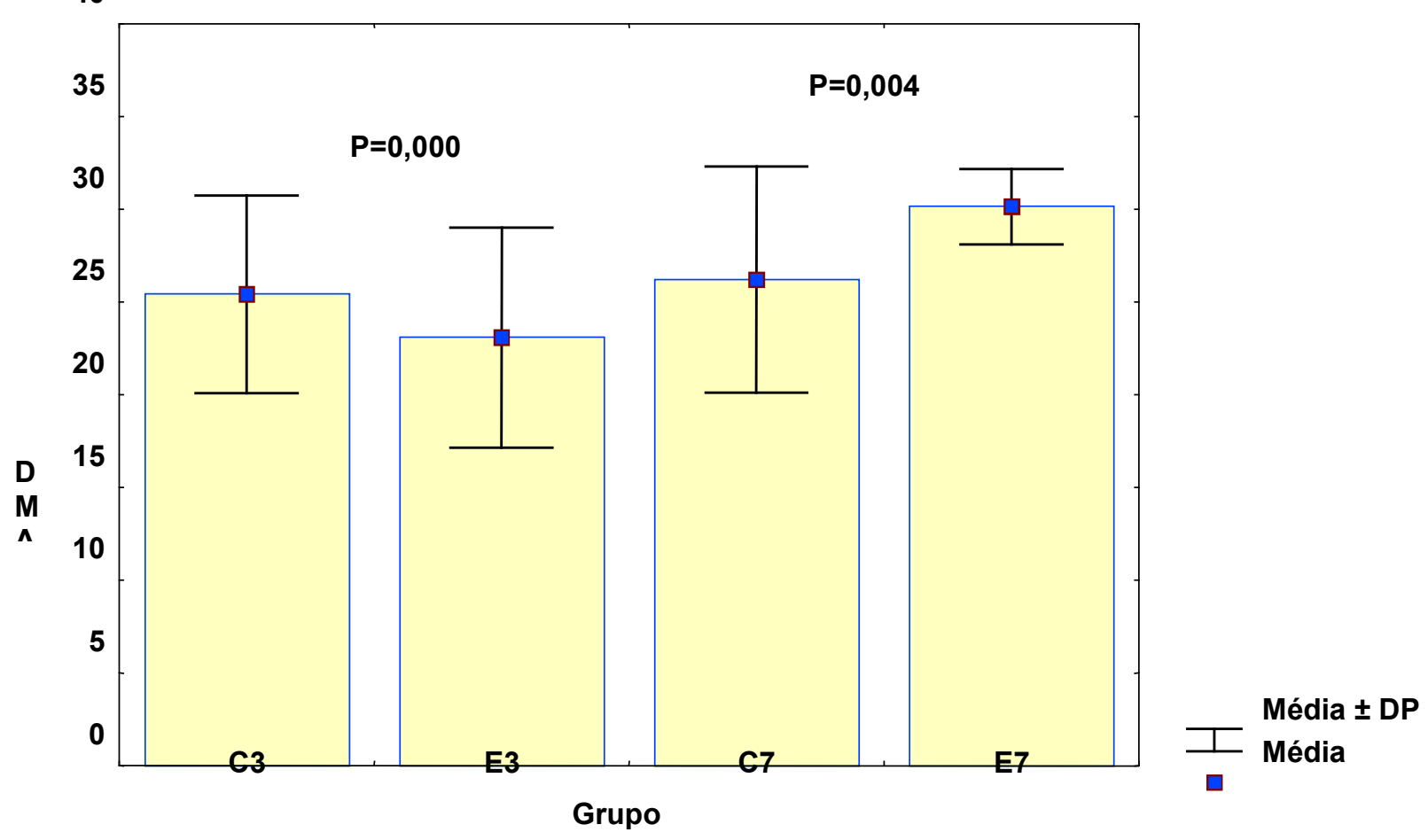

FIGURA 6 - Variável Dmax com média e desvio padrão para os grupos controle e experimento. Legenda: C3 = GC3D, E3 = GE3D, C7 $=$ GC7D, E7 = GE7D

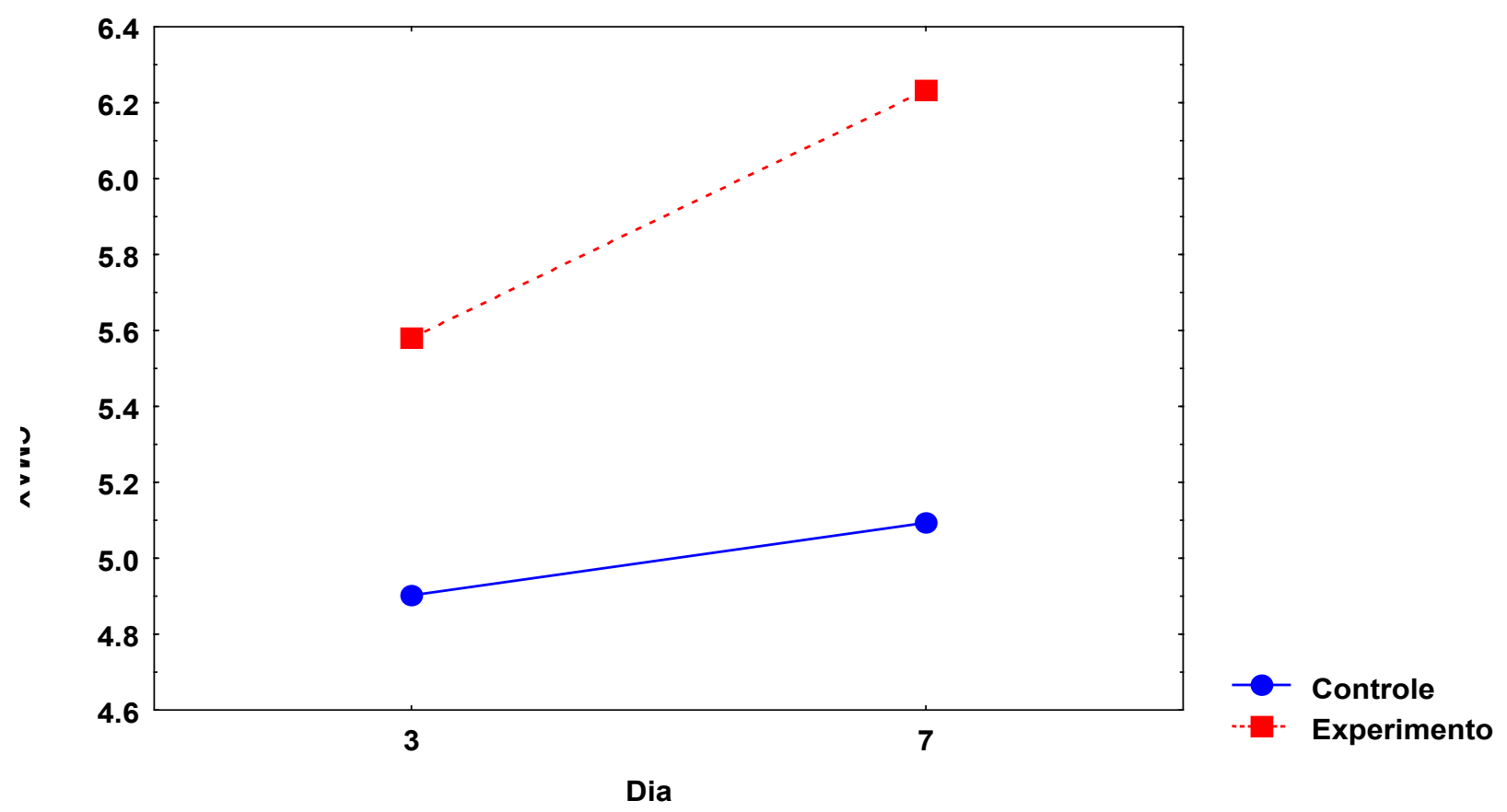

$F(1,33)=0,14 ; p<0,7082$

FIGURA 7 - Teste de Anova (análise de variância) para os grupos controle e experimento entre si em relação à carga máxima no terceiro e sétimo dia. LEGENDA: Cmax = carga máxima; $\mathrm{F}$ = valor do teste da ANOVA para interação; $\mathrm{p}$ = nível de significância 


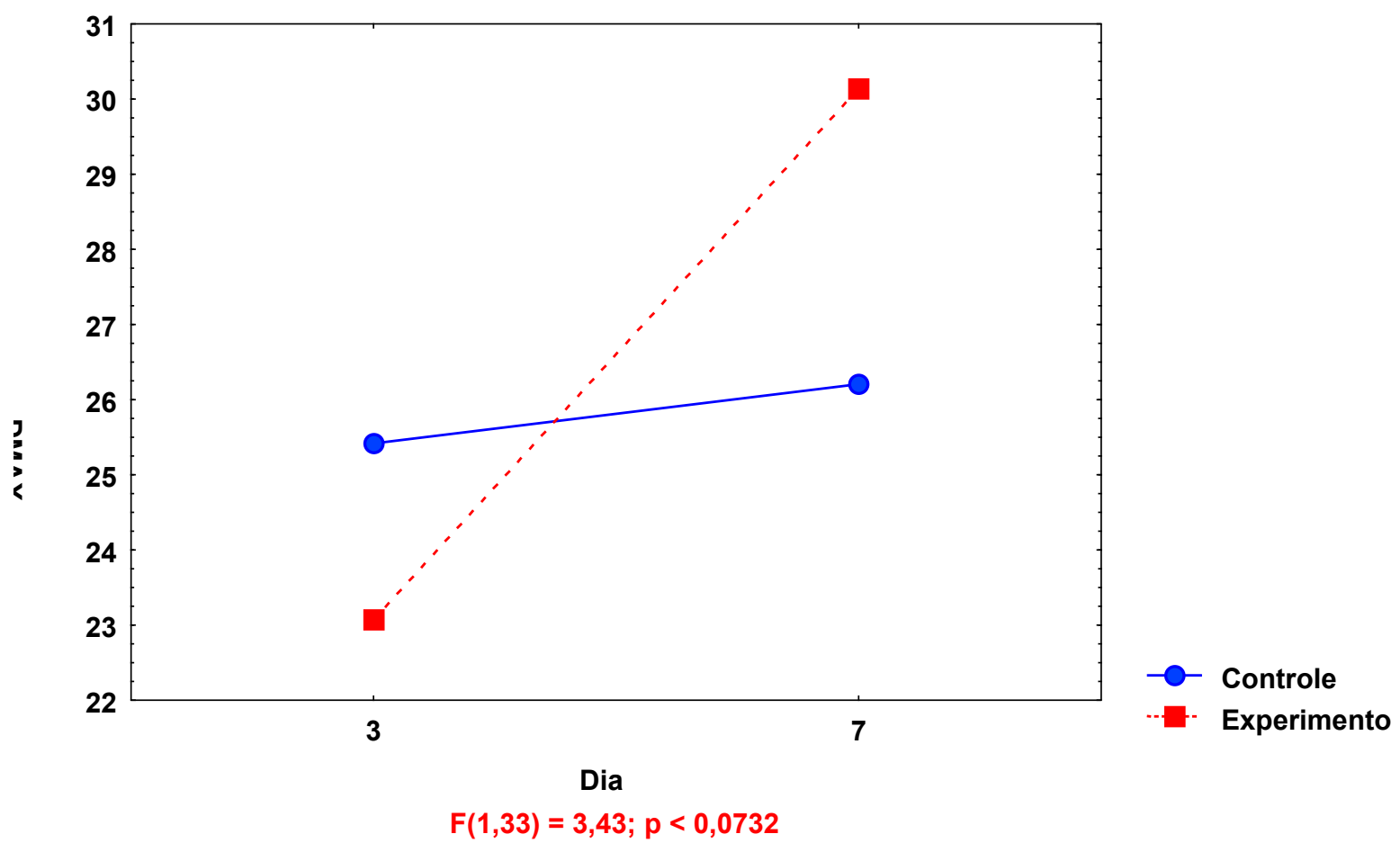

FIGURA 8 - Teste de Anova (análise de variância) para os grupos controle e experimento entre si em relação à deformação máxima no terceiro e no sétimo dia. LEGENDA: Dmáx = deformação máxima; $F$ = valor do teste da ANOVA para interação; $\mathrm{p}=$ nível de significância

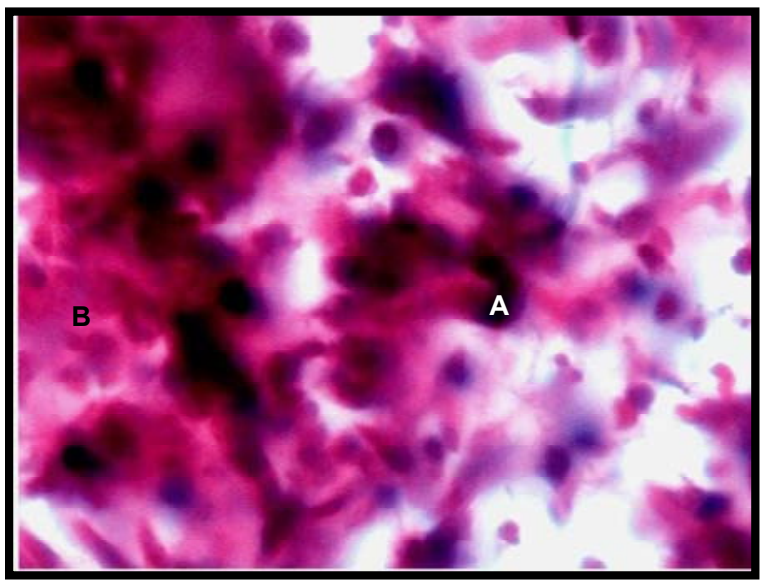

FIGURA 9 - Fotomicrografia de lâmina de um animal do grupo GC3D. NOTA: Lâmina corada pela HE mostrando inflamação crônica acentuada (A - Polimorfonuclear, $\mathrm{B}$ - Edema)

abdominal. A quantificação das aderências entre a linha alba e órgãos abdominais está demonstrada na Tabela 1 .

Os animais mortos no $7^{\circ}$ dia de pós-operatório dos grupos controle e experimento apresentaram em quase sua totalidade processo inflamatório crônico moderado, sendo que apenas em um observou-se processo inflamatório crônico leve (Figuras 11 e 12).

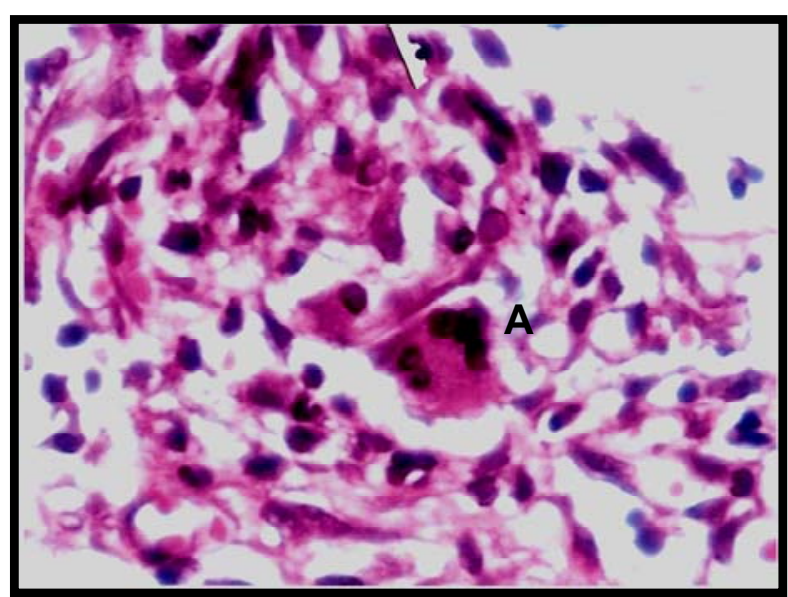

FIGURA 10 - Fotomicrografia de lâmina de um animal do grupo GE3D. NOTA: Lâmina corada pela HE mostrando inflamação crônica moderada (A - polimorfonuclear)

Aplicadas às variáveis histológicas no teste de MannWhitney foi observado efeito marginalmente significativo $(\mathrm{p}=0,086)$ para inflamação aguda aos grupos controle e experimento de três dias e efeito significativo $(p=0,003)$ para reação gigantocelular tipo corpo estranho ao redor do fio de sutura entre os mesmos grupos $(p=0,003)$.

$\mathrm{Na}$ análise dos grupos controle e experimento de sete 
TABELA 1 - Quantificação das aderências entre a linha alba e órgãos abdominais por grupo (escore de adesão de Nair)

\begin{tabular}{lccccc}
\hline \multirow{2}{*}{ Grupos } & \multicolumn{5}{c}{ Escore de adesão de NAIR } \\
\cline { 2 - 6 } & $\mathbf{0}$ & I & II & III & IV \\
\hline GC3D & $50 \%$ & $50 \%$ & $0 \%$ & $0 \%$ & $0 \%$ \\
GC7D & $30 \%$ & $70 \%$ & $0 \%$ & $0 \%$ & $0 \%$ \\
GE3D & $40 \%$ & $60 \%$ & $0 \%$ & $0 \%$ & $0 \%$ \\
GE7D & $70 \%$ & $10 \%$ & $20 \%$ & $0 \%$ & $0 \%$ \\
\hline
\end{tabular}

dias, foi observado diferença significativa $(p=0,023)$ para inflamação aguda.

$\mathrm{Na}$ análise intragrupo (controles de três e sete dias), somente não foi observado efeito significativo $(p=0,094$

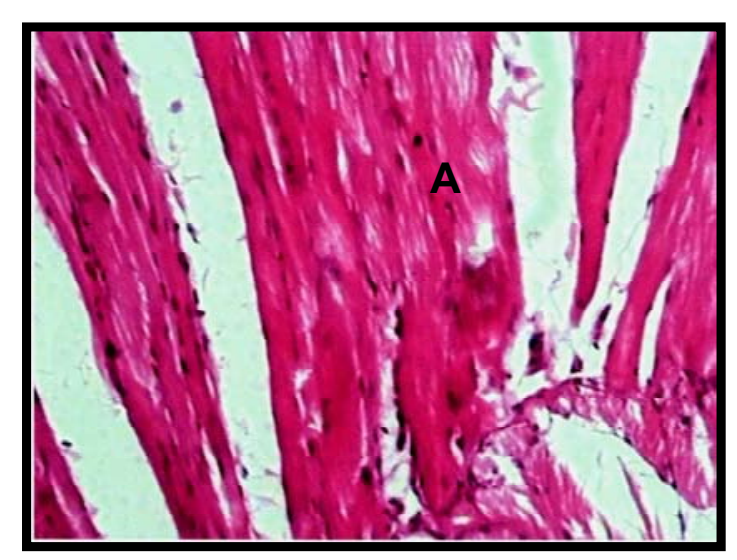

FIGURA 11 - Fotomicrografia de um animal do grupo GC7D. NOTA: Lâmina corada pela HE mostrando colagenização moderada (A - colagenização) e $p=0,05$ respectivamente) para as variáveis inflamação aguda e inflamação crônica.

$\mathrm{Na}$ análise intragrupo entre os grupos experimentos, somente as variáveis reação gigantocelular $(0,002)$ e colagenização $(0,016)$ apresentaram resultados significativos.

\section{Avaliação tensiométrica}

O estudo tensiométrico foi feito na totalidade das peças cirúrgicas retiradas, e todas sem exceção romperam ao nível da sutura.

As curvas de carga versus deformação obtidas para os grupos controle e experimento, após três e sete dias de operados, são apresentados nas Figuras 13 a 16.

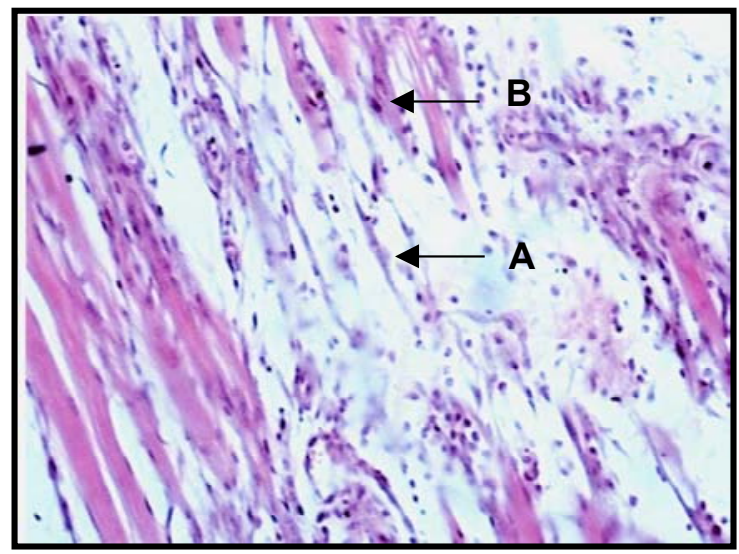

FIGURA 12 - Fotomicrografia de um animal do grupo GE7D. NOTA: Animal marcado na lateral direita mostrando proliferação fibroblástica moderada e polimorfonuclear (A- Fibroblasto, B- Polimorfonuclear)

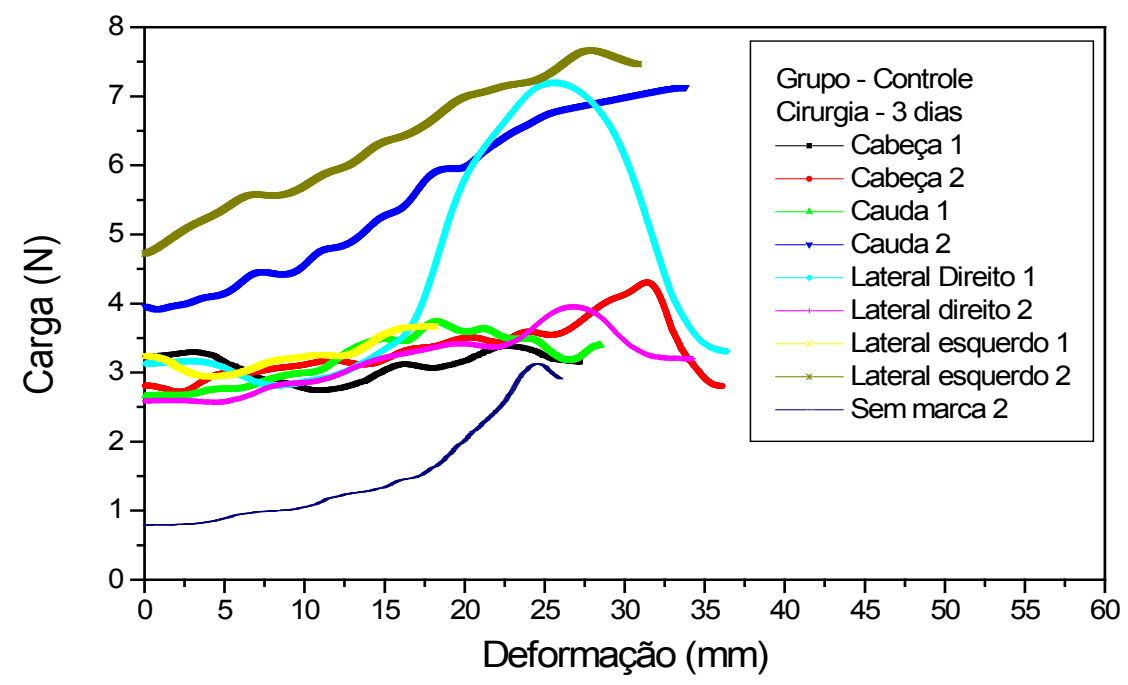

FIGURA 13 - Curva de carga versus deformação no grupo controle de três dias 
Observa-se na Figura 13, que o animal do grupo controle três dias marcado na lateral esquerda apresentou Dmax de 27,74mm com Cmax de 7,68N. Neste mesmo gráfico, o animal sem marca apresentou Dmax de $24,45 \mathrm{~mm}$ com Cmax de $3,12 \mathrm{~N}$ sendo os dois animais extremos neste grupo. A peça cirúrgica de animal sem marca não serviu para o estudo pois foi insuficiente.
A Figura 15 evidencia que a maior Dmax foi de $38,73 \mathrm{~mm}$ com Cmax 3,27N e no outro extremo a Dmax foi de 19,67mm com Cmax de 3,92N, ambos animais sem marca do grupo controle sete dias. $\mathrm{O}$ animal marcado na cabeça teve sua peça cirúrgica insuficiente para o estudo.

A Figura 16 mostra que o animal marcado na lateral esquerda foi o que apresentou maior deformação $(30,21 \mathrm{~mm})$

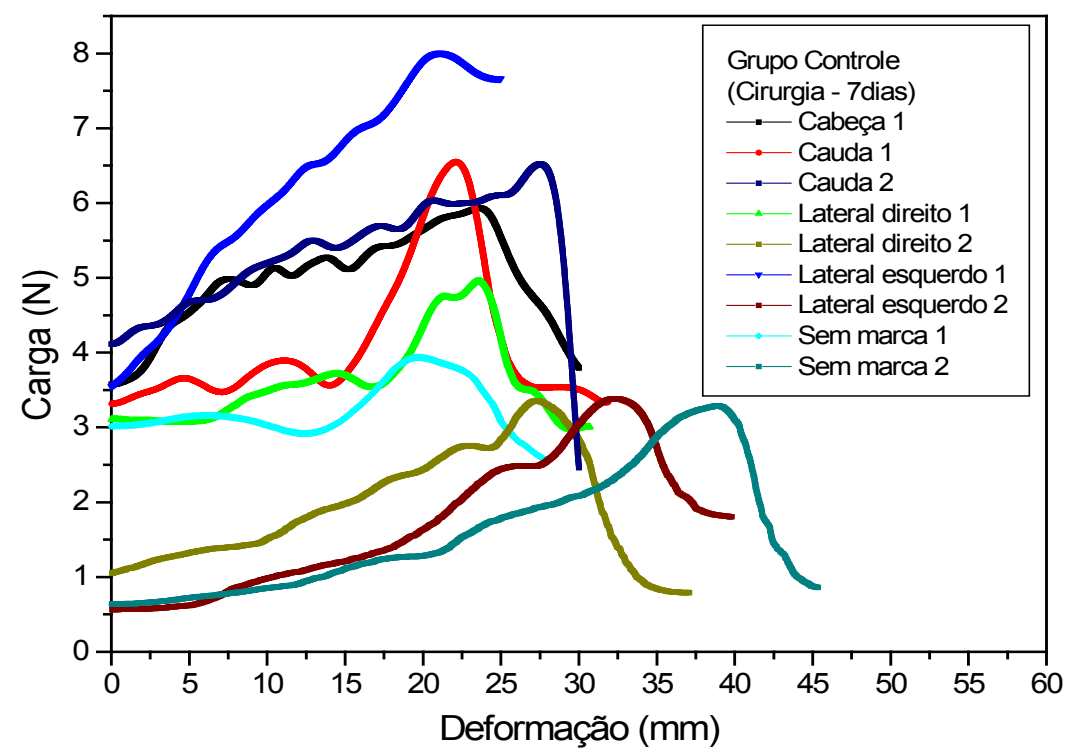

FIGURA 14 - Curva de carga versus deformação no grupo controle sete dias

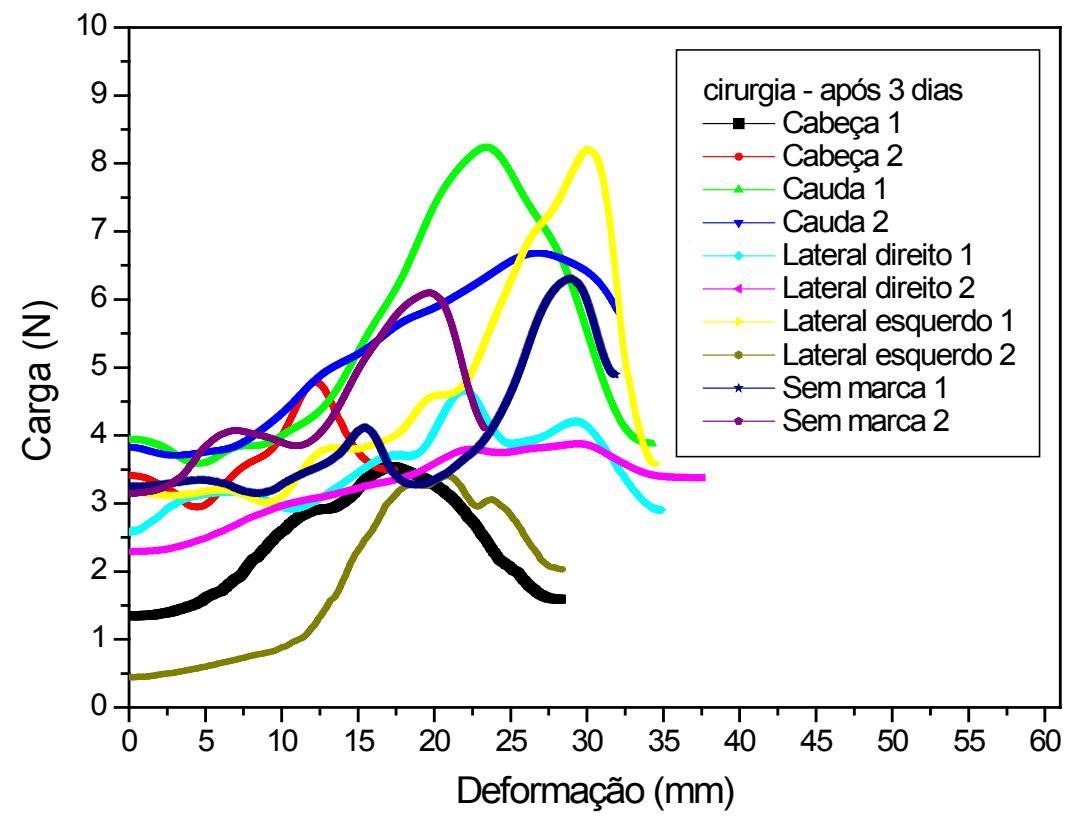

FIGURA 15 - Curva de carga versus deformação no grupo experimento três dias 


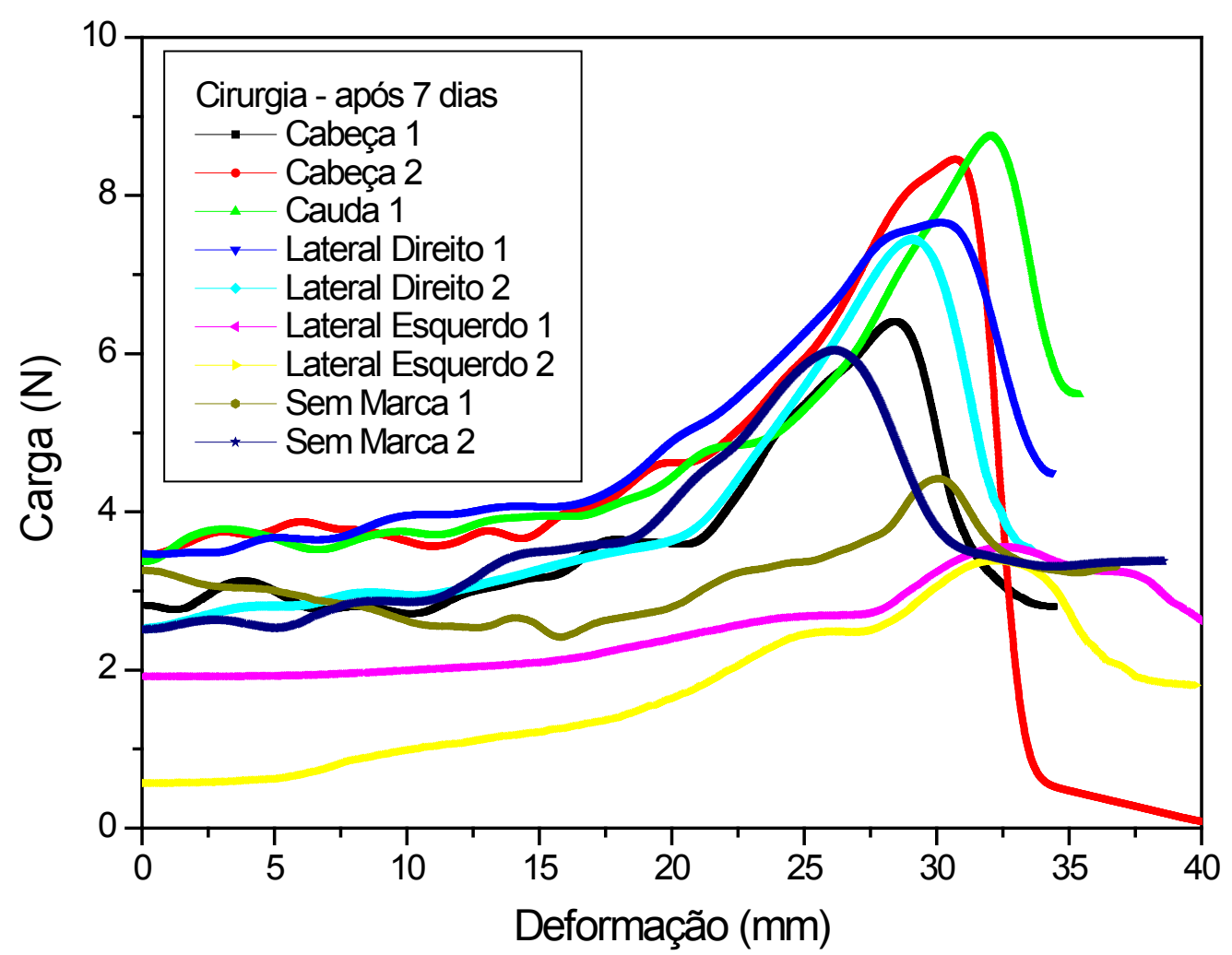

FIGURA 16 - Curva de carga versus deformação no grupo experimento sete dias

com Cmax de $8,2 \mathrm{~N}$, e o animal no outro extremo Dmax de $12,09 \mathrm{~mm}$ com $\mathrm{Cmax}$ de $0,478 \mathrm{~N}$ no animal marcado na cabeça do grupo experimento três dias.

A mesma figura mostra que o animal marcado na lateral esquerda apresentou Dmax igual a 32,41 mm, com Cmax de $3,53 \mathrm{~N}$ e no outro extremo, o animal sem marca foi o que teve menor deformação máxima $(26,18 \mathrm{~mm})$ com Cmax de $6,03 \mathrm{~N}$ no grupo experimento sete dias. Neste grupo o animal marcado na cauda apresentou material insuficiente.

Os valores das propriedades mecânicas dos animais do grupo controle de três dias, indicam carga máxima média de 4.90 e desvio padrão de 1.75 para a respectiva deformação máxima de 25.55 com desvio padrão de 5.32 , enquanto para os animais do grupo controle de sete dias a carga máxima média foi de 5,09 N e desvio-padrão de 1,63 e a deformação máxima 26,23 mm e desvio-padrão 5,74. Todavia, pelo teste $\mathrm{t}$ de Student da análise intra-grupo $(\mathrm{t}=0,226$ para Cmax e $\mathrm{t}=0,292$ para Dmax), não houve diferença significativa entre as médias no grupo controle de três e sete dias.

Os valores das propriedades mecânicas dos animais do grupo controle sete dias indicam: carga máxima com média de 5,09 e desvio padrão de 1,63, deformação máxima de 26,23 e desvio padrão de 5,74.

Os valores para o grupo experimento de três dias foram os seguintes: carga máxima com média de 5,58 e desvio padrão de 1,79 para uma deformação máxima de 23,07 com desvio padrão de 5,93.

A carga máxima com média de 6.23 e desvio padrão de 2.05 , com a respectiva deformação máxima de 30.14 com desvio padrão de 2.04 foi obtida pelos animais do grupo experimento de sete dias de pós-operatório. O teste $\mathrm{t}$ de Student da análise intra-grupo mostrou efeito de dia na cicatrização para a variável $\operatorname{Dmax}(\mathrm{t}=3,38, \mathrm{p}=0,004)$ e para Cmax ( $\mathrm{t}=0,741, \mathrm{p}=0,469)$ não sendo observado diferença significativa

As Figuras 17 e 18 mostram, respectivamente, a carga máxima dada para todos os grupos e a conseqüente deformação adquirida na carga máxima para os mesmos grupos, evidenciando maior resistência para deformação no grupo experimento com sete dias de morte.

\section{Discussão}

A cicatrização de uma maneira geral é assunto relevante para a comunidade científica. $\mathrm{O}$ tema continua sendo alvo de novos estudos visto que, apesar do avanço da medicina atual, é ainda grande o número de complicações decorrentes de problemas inerentes a esse fenômeno biológico. A flora compõe um cenário rico e promissor para estudos científicos visando à descoberta de novos princípios ativos que possam impulsionar a fitoterapia que ainda é incipiente.

Nesta pesquisa a linhagem Wistar foi utilizada por ter 




FIGURA 17 - Carga máxima intergrupos

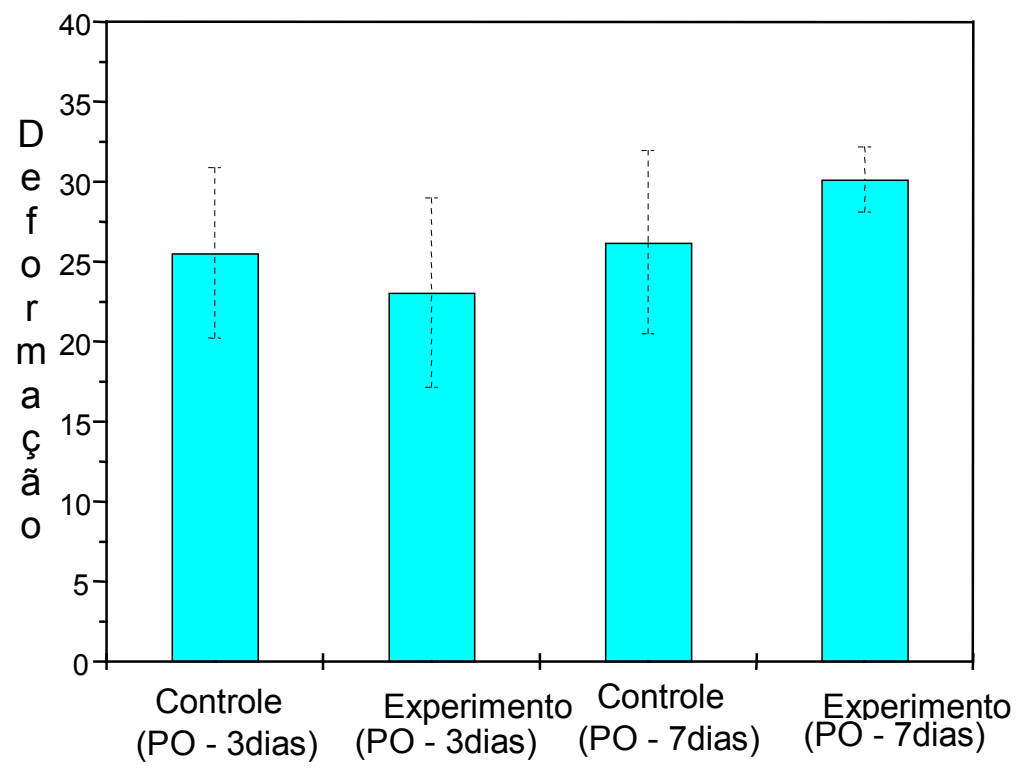

FIGURA 18 - Deformação máxima intergrupos

sido já padronizada anteriormente ${ }^{8,9,10}$ especialmente da parede abdominal ${ }^{11,12,13}$ e mostrou-se eficiente visto que todos os animais sobreviveram até o fim do experimento, não apresentaram complicações pós-operatórias.

Da mesma forma os procedimentos anestésicos foram seguros, de baixo custo, de fácil execução ${ }^{14}$ e artesanal podendo ser recomendado para esse tipo de trabalho.
O polipropileno monofilamentado foi o fio utilizado por já ter sido considerado ideal ${ }^{15}$. Ele resulta em baixa incidência de deiscência e infecção. Neste estudo, os ratos evoluíram sem complicações, corroborando a segurança de seu emprego.

O extrato de Orbignya phalerata foi o fitoterápico escolhido por ser inédito em estudo de cicatrização, não havendo 
na literatura registro de qualquer trabalho sobre esse tema.

A dose escolhida baseou-se em outros estudos realizados que preconizam $50 \mathrm{mg} / \mathrm{kg} /$ peso $^{16}$, e a via de administração intraperitoneal foi determinada pela facilidade e eficiência em sua absorção. Contudo, os resultados podem estar comprometidos devido à incerteza sobre a dose e o veículo certos, embora a escolha da forma aquosa tenha sido por causa do efeito tóxico ao sistema nervoso central pelo uso do meio alcóolico ${ }^{17}$.

A determinação da data da morte dos animais $\left(3^{\circ}\right.$ e $7^{\circ}$ dias) foi baseada em trabalhos sobre cicatrização da parede abdominal $^{18,19}$, permitindo, nesse prazo, eficácia na avaliação histológica e tensiométrica. Na literatura, observa-se que esse tempo é muito variável permanecendo dúvida sobre se é o ideal para realizar esse tipo de estudo. Na opinião dos autores deste trabalho, novos períodos precisam ser experimentados em estudos posteriores.

A macroscopia completa esse estudo, visto que, após a retirada da peça cirúrgica, a visualização direta intraabdominal permite melhores conclusões quanto à reação tecidual nos grupos estudados. Os animais evoluíram sem complicações importantes com presença de aderências frouxas entre a parede abdominal e os órgãos intra-abdominais, o que difere dos achados de Araújo (1997) ${ }^{20}$ que observou alto número de aderências entre a linha alba e as vísceras abdominais. Optou-se pelo escore de aderência de Nair por ser prático e conclusivo muito usado por outros autores.

Por ser quase obrigatório em estudo de cicatrização, escolheu-se a avaliação histológica. A cicatrização em operações experimentais tem nela método determinante também nas conclusões de trabalhos de diversos autores ${ }^{21}$. O corante utilizado para as lâminas foi a hematoxilina-eosina que é universal, de uso rotineiro e eficiente na quantificação e identificação das alterações celulares cicatriciais e que se revelou bom neste trabalho, não havendo necessidade do uso de outro para as conclusões que se propunha aqui chegar.

O predomínio de processo inflamatório crônico granulomatoso, nos grupos controle e experimento de três dias, mostra que não houve diferenças importantes entre eles evidenciando que o extrato de babaçu não teve influência como facilitador no processo de cicatrização, e da mesma forma no grupo de sete dias em que a predominância foi de processo inflamatório crônico moderado.

A proliferação fibroblástica foi mais acentuada no grupo experimento três dias e menos acentuada no de sete. Já no grupo controle três e sete dias, a proliferação foi de grau moderado. O processo de colagenização só foi acentuado em apenas dois animais, um do grupo experimento de três dias e outro do grupo controle de sete.

A reação inflamatória tem importância na cicatrização como demonstram diversos trabalhos, sendo que é nociva se for intensa, pois compromete a microcirculação e a proliferação de fibroblastos ${ }^{22}$. Neste estudo, predominou reação inflamatória leve a moderada, com neoformação capilar.

Evidencia-se, desta forma, que o extrato aquoso de babaçu tem efeito antiinflamatório e não efetivamente cicatrizante, como também demonstram trabalhos de alguns autores $^{5,16}$.

Complementando a avaliação histológica, a tensiome- tria foi escolhida como segundo elemento de avaliação da cicatrização. Diversos trabalhos têm realizado esse método de aferição sobre cicatrização da parede abdominal ${ }^{12,21}$, sempre o considerando bom parâmetro complementar. Ele foi padronizado por Tognini et al. (1998) ${ }^{2}$ utilizando um equipamento semelhante embora com velocidade menor $(10 \mathrm{~mm} / \mathrm{min})$ na tentativa de evitar ruptura das extremidades das peças cirúrgicas.

No presente estudo, observou-se que o grupo experimento sete dias obteve melhor resistência à tensão exercida sobre a peça cirúrgica em que teve carga máxima maior e deformação máxima mais prolongada, em semelhança a outros estudos ${ }^{20}$.

\section{Perspectiva}

A rica flora brasileira permite exploração científica infinita, visto que a diversidade do biosistema do país é muito grande. Diante desse estudo, mesmo com resultados modestos na comprovação de possível ação cicatrizante, a Orbygnia phalerata merece continuidade em pesquisas usando enfoques diversos, como novas concentrações, novos modos de administração, nova posologia e novos períodos de observação. A sinalização positiva aqui conseguida estimula a continuidade dessas pesquisas que, ao longo do tempo, poderão determinar o real valor dela e sua possível utilização em humanos com intenção de auxiliar o mecanismo de cicatrização de tecidos e órgãos.

\section{Conclusão}

As avaliações macroscópica e histológica não mostraram diferenças significativas entre os grupos experimento e controle. Quanto à avaliação tensiométrica, o grupo experimento de sete dias apresentou diferença significativa em relação ao controle de mesmo período de pós-operatório, sugerindo indícios de que o uso do extrato administrado intraperitonealmente favorece o processo de cicatrização.

\section{Referências}

1. Robbins S. Patologia estrutural e funcional. $6^{\mathrm{a}}$ ed. Rio de Janeiro: Guanabara Koogan; 2000.

2. Tognini, Joäo Ricardo F; Goldenberg, Saul; Simöes, Manuel de Jesus; Sauer, Leandro; Melo, Rosana Leite de; Ortiz, Pedro Leopoldo A. Efeito do diclofenaco de sódio na icatrização da parede abdominal de ratos. Acta Cir Bras. 1998; 13:167-71.

3. Lazarus GS, Brown RS, Daniels JR, Fullmer HM.. Human granulocyte collagenase. Science. 1968; 159:14835.

4. Chagas AP. Atividade do mesocarpo babaçu (Orbignya phalerata) sobre o desenvolvimento tumoral e a população de linfócitos B. São Luís: UFMA; 2001.

5. Silva BPS, Parente JP. Na anti-inflamatoriy polysacharide from orbginya phalerata. Fitoter. 2001; 72:887-93.

6. Moura ACA, Silva ELF, Fontes SGF. Avaliação do efeito de Orbignya phalerata MART (babaçu)em modelos experimentais. Recife, 2002. 
7. Nair SK, Bhat IK, Aurora AL. Role of proteolytic enzyme in the prevention of postoperative intraperitoneal adhesions. Arch Surg. 1974; 108:849-53.

8. Simões MJ,Uzunian A, Mora OA;Sasso,Silva W.Aspectos ultra-estruturais do processo de reparação da pele de ratos albinos. Rev Paul Med. 1985;103:123-6.

9. Fatureto MC. Aspectos morfológicos do processo inflamatório provocado por fio de categut simples no subcutâneo de ratos tratados com diclofenaco sódico.[Dissertação-Mestrado].São Paulo:Escola Paulista de Medicina; 1988.

10. Prandi Filho W. Aspectos morfológicos e morfométricos do processo inflamatório provocado por fio de algodão no subcutâneo de ratos tratados com diclofenaco sódico. [Dissetação-Mestrado] São Paulo:Escola Paulista de Medicina; 1988.

11. Queiroz, Valdeir Fagundes de; Silvado, Rubens Augusto Brazil; Simöes, Manuel Jesus; Goldenberg, Saul. Aspectos morfológicos e morfométricos da reação tecidual à película celulósica introduzida no plano muscular da parede abdominal de ratos. Acta Cir Bras. 1989; 4:144-8.

12. Seid MH, McDaniel-Owens LM, Poole GV Jr, Meeks GR. .A randomized trial of abdominal incision suture technique and wound strength in rats. Arch Surg. 1995; 130:394-7.

13. .Muñoz Fernandez, Pedro; Martins, José Luiz; Novo, Neil Ferreira; Gomes, Paulo Oliveira; Goldenberg, Saul. Estudo comparativo da resistência à tração das cicatrizes nas laparotomias longitudinais e transversais em ratos. Acta Cir Bras. 1996; 11:133-7.

14. Rodrigues, Lusmar Veras; Simöes, Manuel Jesus; Teves, Danilo Carreiro de; Goldenberg, Saul. Aspectos morfológicos e morfométricos do processo inflamatório provocado por fio de categute simples subcutâneo de ratos tratados com cetoprofeno. Acta Cir Bras. 1989; $4: 152-7$.
15. Hodgson NC, Malthaner RA, Ostbye T. The search for na ideal method of abdominal fascial closure: a metaanalysis. Ann Surg. 2000; 231:436-42.

16. Maia MBS. Estudo de atividade anti-inflamatorio e outros efeitos farmacológicos relacionados de orbignya phalerata Mart.. [Dissertação - Mestrado]. Fortaleza: Universidade Federal do Ceará, Departamento de Fisiologia; 1987.

17. Lagarto Parra, Alicia; Tillán Capó, Juana; Vega Montalvo, Raiza; Cabrera González, Yolanda. Toxicidad aguda oral del extractos hidroalchólicos de plantas medicinales. Rev Cubana Plants Med. 1999; 4:26-8.

18. Shahan MH, Chuang AH, Brennan WA, Dirksen TR, Van Dyke TE, McPherson JC. The effect of chlorhexidine irrigation on tensile wound strength. J Periodontol. 1993; 64:719-22.

19. Poole GV Jr, Meredith JW, Kon ND, Martin MB, Kawamoto EH, Myers RT. . Suture technique and woundbursting strength. Am Surg. 1984; 50:569-72.

20. Araújo GF. Implante de tela de algodão na parede abdominal de ratos. [Tese - Doutorado]. São Paulo: Escola Paulista de Medicina; 1997.

22. .Tognini, Joäo Ricardo F; Fagundes, Djalma José; Novo, Neil Ferreira; Juliano, Yara. Estudo biomecânico e morfológico da cicatrização da parede abdominal sob ação de meloxicam. Acta Cir Bras. 2000; 15 146-155.

22. Mazzini DL, Mantovani M. Fechamento da parede abdominal com afastamento parcial das bordas da aponeurose utilizando sobreposição com telas de vicryil ou marlex em ratos. Acta Cir Bras. 1999; 14:1: 28-34.

\section{Correspondência:}

Rua das Cegonhas, Quadra 14, Lote 4, Casa 11

Cond. Portal do Atlantico

Olho D'Agua - São Luis - MA

CEP: 65065-100
Conflito de interesses: nenhum Fonte de financiamento: Capes

Recebimento: 19/02/2005

Revisão: 06/06/2005

Aprovação: 10/06/2006

\section{Como citar este artigo:}

Brito Filho SB, Matias JEF, Stahlke Jr HJ, Torres OJM, Timi JRR, Tenório SB, Tâmbara EM, Carstens AG, Campos RV, Myamoto M. Análise da cicatrização na linha alba com uso de extrato aquoso de Orbignya phalerata (babaçu). Estudo controlado em ratos. Acta Cir Bras. [periódico na internet] 2006;21 Supl 3:76-88. Disponível em URL: $\underline{\text { http://www.scielo.br/acb }}$ 